\title{
Improving Bus Route Design Using Stop Balancing and Community-level Data
}

\author{
$\coprod_{\text {Justin McKetney }}{ }^{*}, \underline{\text { Edna A. Trujillo }}^{2 *}, \underline{\text { Megan Tabbutt }}^{3,4}$, \\ Brittany Baur $^{5}$
}

1Department of Biomolecular Chemistry, University of Wisconsin - Madison, Madison, WI

2Department of Chemistry, University of Wisconsin - Madison, Madison, WI

${ }^{3}$ Department of Physics, University of Wisconsin - Madison, Madison, WI

${ }^{4}$ Department of Computer Science, University of Wisconsin - Madison, Madison, WI

${ }^{5}$ Wisconsin Institute for Discovery, University of Wisconsin - Madison, Madison, WI

*Authors contributed equally

https://doi.org/10.38126/ISPG180109

Corresponding author: mcketney@wisc.edu

Keywords: public transportation; transit policy; equitable transit; route design; bus stop balancing; transit efficiency; data-driven transit

\begin{abstract}
Executive Summary: Public transportation brings numerous benefits to communities when it provides people with mobility and access to opportunities. A well-designed and widely utilized system is required for regions to gain access to these benefits. Transit policies must be efficient, relevant to their specific region, and take into consideration how residents utilize public transit. In this paper, we focus on the implications of bus stop balancing and route schedule design for the Madison Metropolitan Transit in Madison, Wisconsin. We discuss where populations live and work to illustrate potential servicing barriers that limit access to employment centers. We recommend adopting standardized spacing between stops of 1000 2500 feet to increase transit speed and reliability with a particular focus on areas with low car ownership. Finally, we spotlight how transit services can be expanded to include nontraditional commuters. The adoption of these suggested improvements will lead to faster transit times with improved reliability and more equitable service within the Greater Madison Area.
\end{abstract}

\section{Introduction}

For rapidly growing cities, public transit benefits residents by offering mobility, reducing pollution and congestion, and stimulating the economy. It was estimated that in $2019,82.46 \%$ of the population in the United States (350 million people) lived in cities and urban areas (Pletcher 2020). However, after the economic downturn of 2010, the distance between residence and employment centers has increased and there has been a drastic demographic and economic shift away from urban cores (Kneebone and Holmes 2016). While some commuters rely on public transportation to travel between home and work, the majority of Americans (86\%) use personal autos (Felix 2019). However, heavy car use for commuting purposes has detrimental social and environmental effects (Felix 2019; Litman 2013). According to the United States Environmental Protection Agency (EPA), the transportation sector produces the largest source of carbon dioxide emissions from fossil fuel combustion (EPA 2020). Additionally, studies have shown that the unpredictable nature of highly congested commutes increases stress levels for car users in comparison to those using public transportation systems (Legrain et al. 2014). In one study, researchers found that car users were twice as likely to report being dissatisfied with their commute than those who used public transit (Zeid 2009). Surprisingly, higher population density within a city is not correlated with increased car utilization. Rather, a recent publication concluded that the main influencers of car use and congestion in an urban 
setting is the size of the region and the availability of public transportation options (Verbavatz and Barthelmey 2019). For regions to reap the numerous benefits of public transit, a well-designed and wellutilized system must be in place.

The use of public transit, also referred to as ridership, has decreased in response to a thriving car industry. Public transportation has not adequately met riders' needs when compared to personal automobiles (Mallett 2018; Shrag 2002). In addition, road infrastructure has been constructed to facilitate car use over bus lines. Low ridership can be associated with relatively low gas prices, easy access to auto loans, and ride-share apps' popularity (Mattson 2008; Atiyeh 2017; Hall et al. 2018). Sprawling, carbased urban development makes private-car use highly flexible, accommodating schedules more easily. On a limited budget, public transit systems must identify what values - ridership, coverage, or perhaps a balance of both - to prioritize (Walker 2012). The most significant challenge transit agencies face, however, is identifying and addressing the diverse needs of current and potential riders (Clark 2017). Transit systems must consider the relationship between transit access needs and regional demographics, labor patterns, and commuting strategies (U.S. Department of Transportation 2020). Public transit is meant to provide equitable transportation services, particularly to vulnerable communities that are more likely to rely on it (Welch and Mishra 2013). However, the geography and developmental history of a region challenges transportation agencies in establishing more inclusive planning practices (Rodrigue 2013). For example, the unique geography of an isthmus has constrained the development of roadway systems for the rapidly growing urban city of Madison (WI). Attempting to meet increased travel demands and congestion, the City of Madison is implementing a new Bus Rapid Transit (BRT) system that provides transit corridors through the centralized downtown that extend to the east and west sides of the city. Unfortunately, the two large lakes that shape the isthmus occlude deployment of similar services to the city's north and south areas. Thus, regional geography and existing developments challenge transit planners to find creative approaches to achieve their objectives.
One approach for implementing regional transit policies is through federally-mandated and funded metropolitan planning organizations (MPOs) (Katz et al. 2003; Bailey and Puentes 2003). MPOs are local government agencies that coordinate regional groups with state and federal officials to identify short and long-term transportation planning goals in urbanized regions of greater than 50,000 people. By prioritizing projects and identifying the needs of an expanding metropolitan area, MPOs determine how limited funds will be allocated. The decisions of where transportation investments are made shapes residents' quality of life and influences the ability for residents to conveniently and safely access opportunities (Sanchez 2006; Williams et al. 2019). Transit mobility is therefore a complex interaction of land use, cost-effectiveness, and transit accessibility where the social and economic development of a region is intricately tied to how residents utilize public transit.

In this paper, we focus on the implications of bus stop balancing and route schedule design to meet the diverse needs of commuters in Madison, Wisconsin. We chose the City of Madison as a representative medium-sized urban region experiencing rapid population growth. Unlike many urban areas, Madison's central downtown is not directly connected to the Interstate Highway System, thus, necessitating strategies for managing and mitigating congestion. Our aims are to highlight how low capital expenditure improvements like bus stop balancing can result in faster transit and improved reliability and amenities with the currently used resources. Additionally, we investigate how route networks currently service communities in the Greater Madison Urban Area. We provide an analysis of where populations live and work to illuminate servicing barriers to employment centers. Our results suggest that Madison Metropolitan Transit (Metro Transit) can improve accessibility by modifying its route network in both ways that are standardized and those that are specific to communities that work nontraditional hours or have limited car access. While recognizing the significant benefits of Metro Transit, we highlight areas where improvements can benefit the culturally and socioeconomically diverse residents of the City of Madison. 


\section{Overview of metro transit}

Madison Metropolitan Transit (Metro Transit) currently serves almost 250,000 residents across 11 municipalities in the greater Madison Urban Area. The geography of the Madison area has consistently proved challenging to all forms of motor transportation, with two lakes forming a narrow isthmus where the Wisconsin state capitol, the downtown area, and the University of Wisconsin Madison (UW-Madison) campus are all located (Figure 1). For much of the $20^{\text {th }}$ century, Metro Transit operated using a highly centralized radial network, where all transfers occurred in the downtown area. The result was an aggravated congestion problem leading to slower and less consistent transport and a decline in transit ridership. In 1998, Metro Transit attempted to decentralize away from the downtown by establishing four peripheral transfer points (North, South, East and West). Since then, Metro Transit has seen a consistent increase in ridership with almost 13 million trips provided in 2019 (Metro Transit 2020). As ridership has increased, Metro Transit has also expanded its route network, growing from 23 to 71 fixed routes between the years 1997-2019. The service expansion has led to a greater operating cost per trip, peaking at $\$ 3.85$ per passenger in 2019. Still, Metro Transit maintains a lower cost per passenger trip than the national average ( $\$ 4.90$ per trip) (APTA 2020). Calculating the passenger trips per operating mile can provide insight into whether a bus system has overextended its service area beyond demand (d'Arcier 2014). Metro Transit experiences distancenormalized utilization of 2.26 trips per mile, which is on par with the 2.5 trips per mile average of the country as a whole (APTA 2020), despite its relatively wide service area. Planning, coordination, and operation of Metro Transit is performed by several organizations to meet the transit needs and objectives of the towns, villages, and cities serviced.
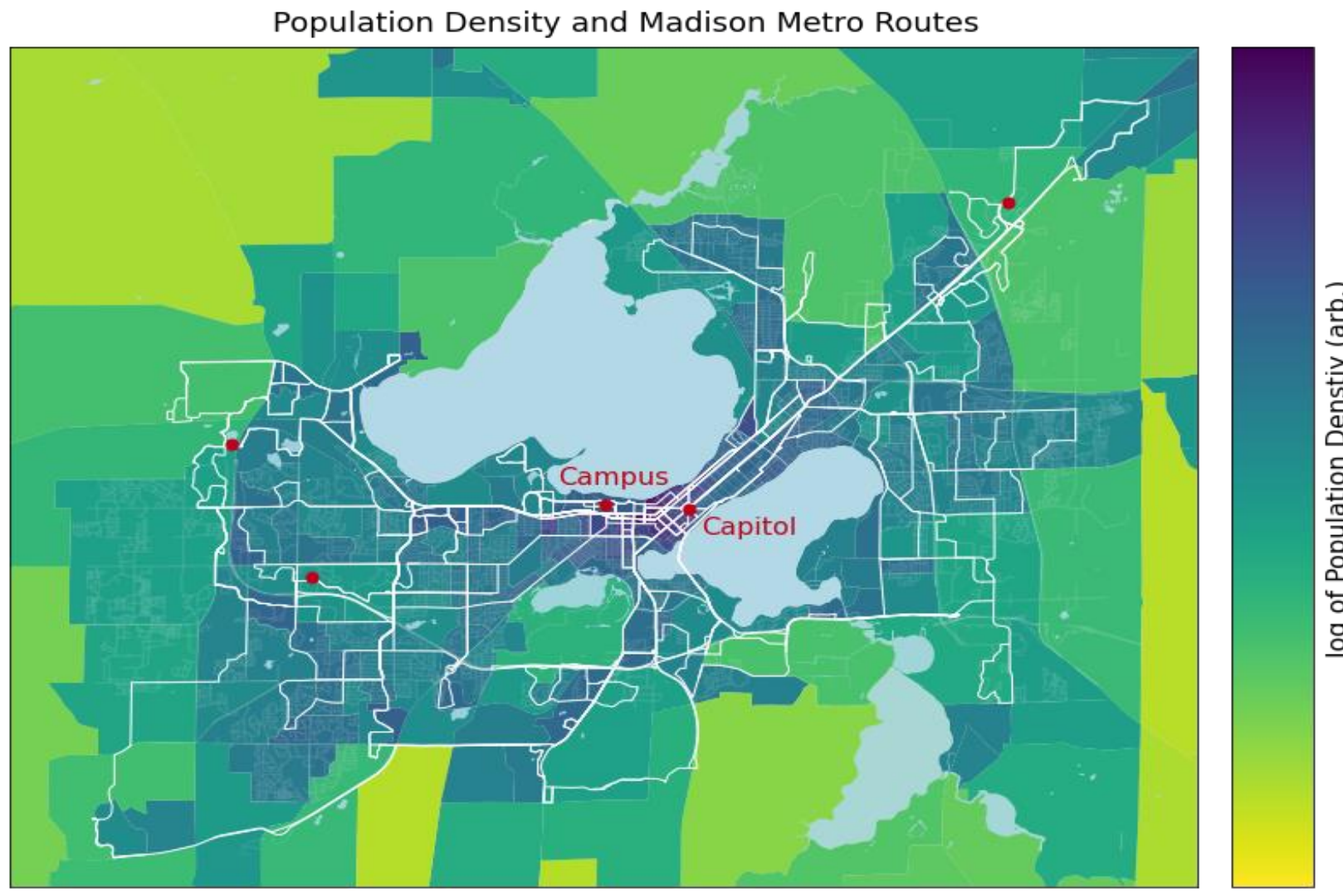

Figure 1: Madison Area and Metro Overview. A system map of Madison Metro overlaid on a population density map. The bus system uses a mostly radial design emanating from the isthmus where the state capitol and university are located. This is also the most densely populated region of Madison. The density falls off with distance from the capitol as do the available bus routes. The four lakes add a layer of complexity to the route designs as well. Red dots indicate substantial employment centers and include the UW-Madison campus and the State Capitol. (City of Madison n.d.; U.S. Census Bureau 2019). 
The Metro Transit bus fleet is owned and operated by the City of Madison, with Metro Transit's general manager reporting directly to the Mayor of Madison. The Madison Common Council is an elected body that appoints members to the Transportation Committee to exercise legislative control over Metro Transit, including items related to budgeting and finance. The Greater Madison MPO is appointed by a combination of local, county, and state officials, to plan and execute a wide variety of transportation projects including those related to Metro Transit across municipalities, county, state, and federal agencies. While the MPO excels at coordinating large scale projects like bus rapid transit and resources like buses and drivers across multiple cities, many times it falls short in more targeted, data-driven action at the neighborhood level(Nelson et al. 2004).

Routes included in the Metro Transit network vary substantially in both frequency and distance between
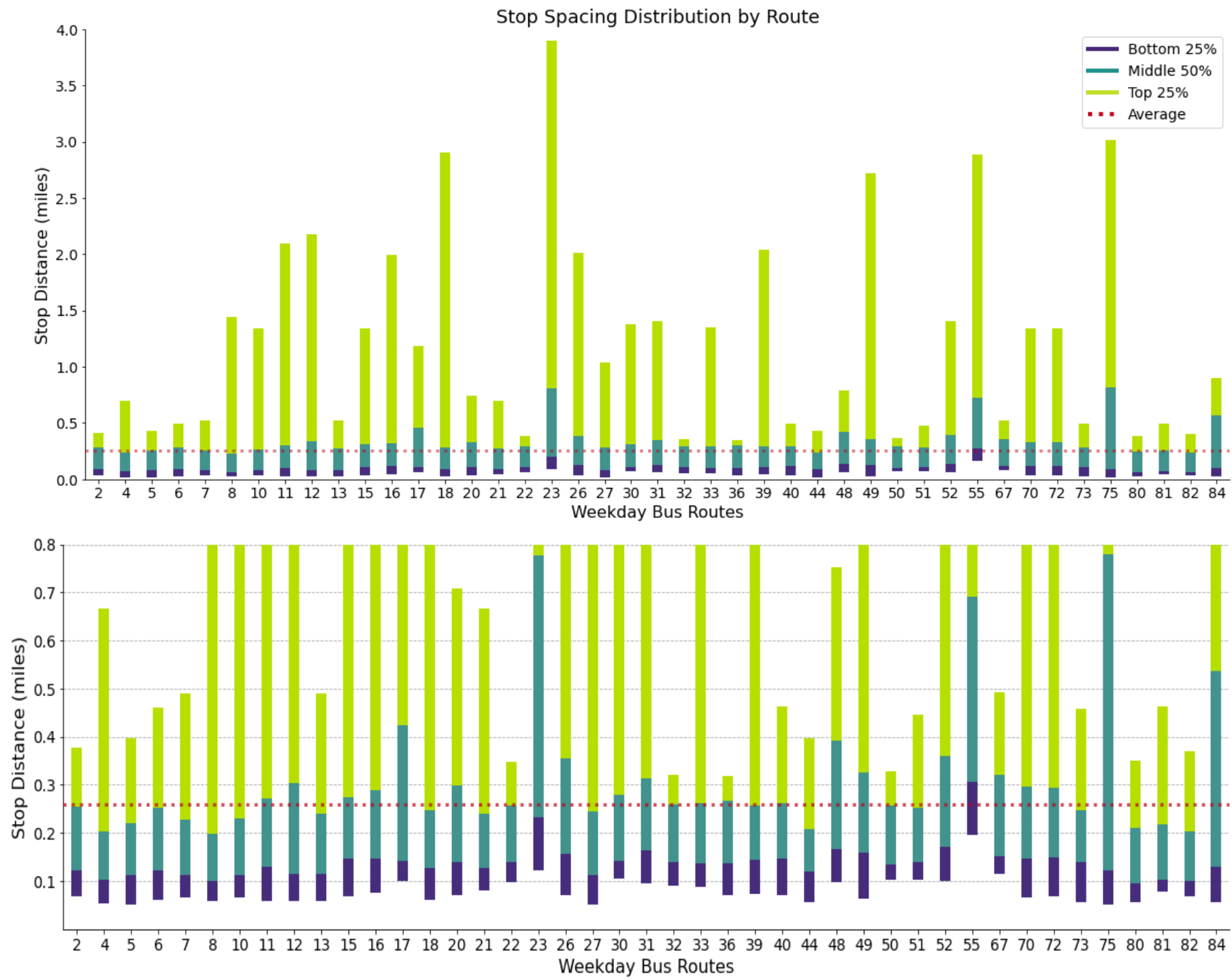

Figure 2: Route Spacing Quartiles. Quartiles of stop spacing for weekday routes on Madison Metro. Top 25\%, middle $50 \%$, and bottom $25 \%$ are shown in green, teal, and purple, respectively. Routes vary in duration, frequency and service area throughout the day. An average over all times of day for weekday only trips is shown here. An average over all weekday trips for all routes is shown by the horizontal dashed red line. The abnormally high top $25 \%$ bars, such as can be seen on routes 23 and 75, reflect routes with "limited stop zones" in which the bus will make no stops for several miles in order to increase speed and distance covered. (City of Madison n.d.; U.S. Census Bureau 2019. 


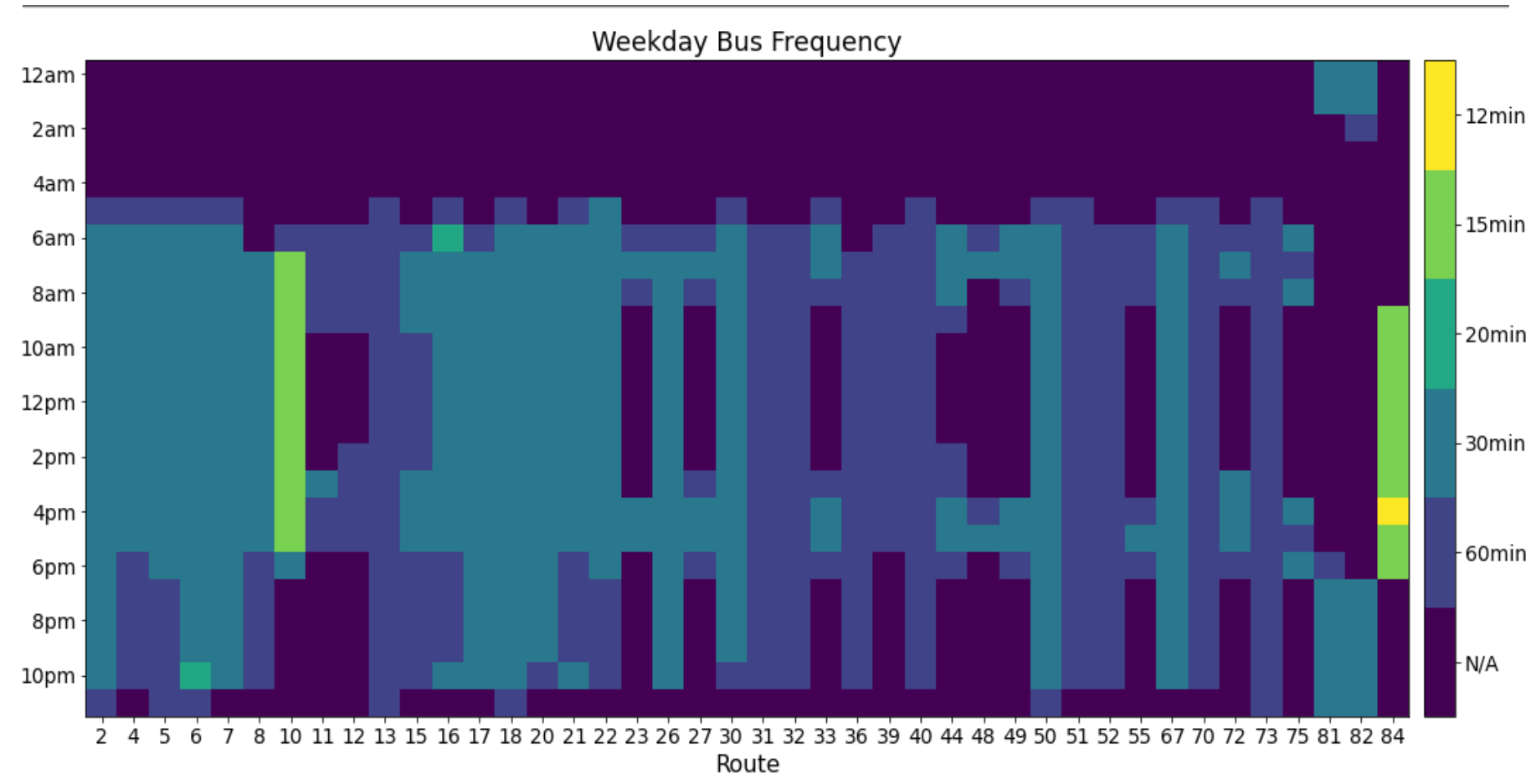

Figure 3: Route Frequency. Weekday route frequency, defined as the period of time between buses at a given stop for a specific route, can be seen for every hour and route. Route 80 is omitted as it is a specialized route used by the University to transport students around campus only during classes and comes every $\sim 6 \mathrm{~min}$. The time that each route runs was determined by analyzing the median stop in each route. Peak and Off-Peak service can be seen clearly. For instance, route 36 runs every 60 min all day, while route 55 only has peak service and does not run in the middle of the day. (City of Madison n.d.).

stops. Although the mean stop distance across all routes in the network is 0.22 miles $(1320 \mathrm{ft})$ several routes, such as the 44, 27 and 4, have considerably shorter mean distances (Figure 2). Even routes with large average spacings, such as route $16 \& 18$, include segments of highly proximal stops with minimal distances of 0.08 and 0.07 miles, respectively (Figure 2).

Overall, bus service is considered to be "low frequency" by the Transportation Advisory Board (Pine and Niemeyer 1998), with more than 10 routes only receiving hourly service (Figure 3 ). The service schedule centers around a nine-to-five workday, with several routes providing service exclusively in two traditional commuting windows typically described as "peak hours": 6-9 am and 4-7 pm (Figure 3). Route headways, or the time between buses from a certain route arriving at a stop, of less than 30 minutes are rare across the network. These shorter route headways are largely limited to routes that transport students across the UW campus area.

\section{Dane County community}

\section{i. Demographics}

Dane County, which includes all municipalities serviced by Madison Metro, contains a highly diverse set of communities. Dane County contains a higher proportion of non-white, non-English speaking residents than Wisconsin overall (U.S. Census Bureau 2019(a)). The diverse cultures found within the county lead to varied occupations, travel habits, and general perceptions about public transportation. Although the highest population density occurs immediately abutting the UW-Madison campus, the vast majority of service population for Metro Transit resides outside the isthmus area. These peripheral neighborhoods, including the surrounding cities of Middleton, Fitchburg and Verona, have seen their population increase over the last decade (U.S. Census Bureau n.d.). The highest concentration of African American and Latino residents live in northern and southern Madison outside of the busy downtown service corridor (Figure 4). 


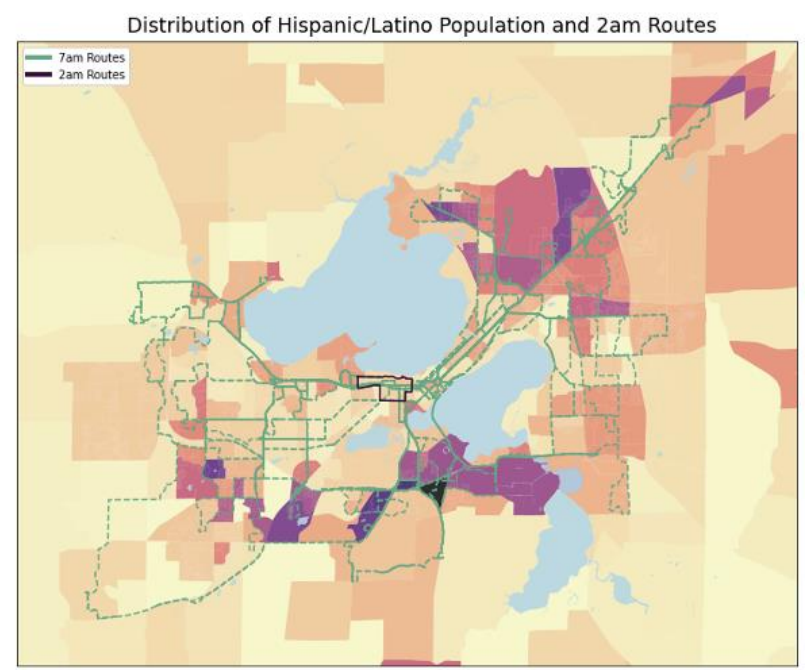

Distribution of Hispanic/Black Population and 2pm Routes

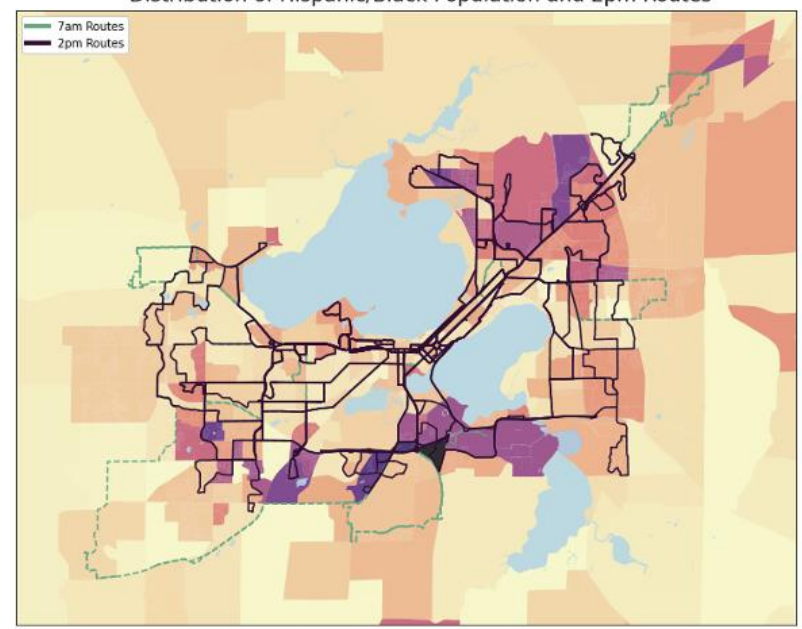

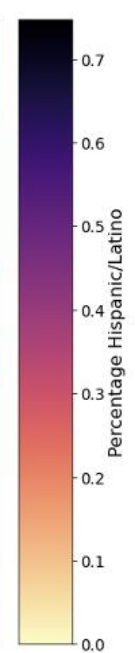

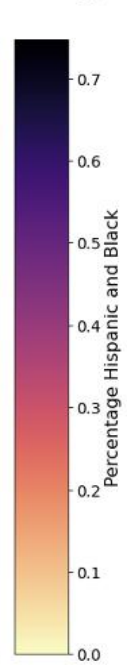

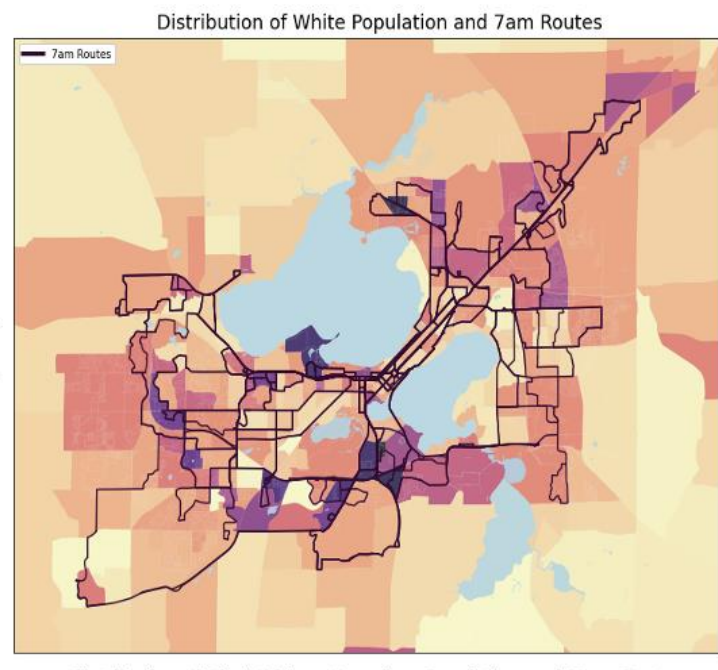

Distribution of Black/African American Population and 10pm Routes

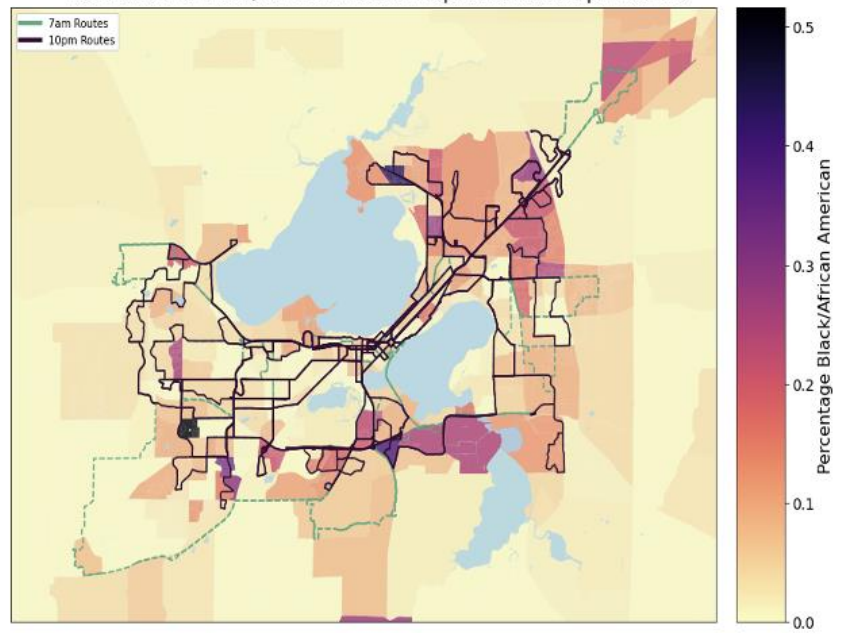

Figure 4: Ethnic Demographics and Route Service. Considering the interesting times found in Figure 4, the percentages of various Ethnic groups was plotted with the possible routes for that time overlaid. As seen in Figures 3 and 4, 7am is a peak of service across all routes and a peak of workers departing. These routes are shown in green dashed lines above in all plots. Contrasting with the peak service, the given service for an hour can be seen in dark purple. For instance, it can be seen that at $10 \mathrm{pm}$, where a Black worker has the highest discrepancy likelihood for departure to work, in a neighborhood with a large Black population, $30 \%$, on the south side of Madison, there are two routes that no longer run by $10 \mathrm{pm}$ that did at $7 \mathrm{am}$ on weekdays. (City of Madison n.d.; U.S. Census Bureau 2019).

\section{ii. Employment}

The increased diversity of residents outside of the downtown area produces a variety of commuting habits across the greater Madison Area. Although the isthmus contains the highest density of jobs, several other significant employment centers exist along the beltline highway and in northern Madison (Figure 1). Residents of Dane County are three times more likely to take public transit to work than residents of Wisconsin as a whole (U.S. Census Bureau 2019(a)), although driving to work is still the most common form of commuting. Black and Latino Wisconsinites are more likely to leave for work at midday or late at night than white Wisconsinites (Figure 5) (U.S. Census Bureau 2019(b)). Car density on a per capita basis is lowest in the area immediately surrounding the UW-Madison campus, driven by the large student population. Student transport in this area is supported by some of the highest frequency bus service in the network. We also observe relatively low car density in the southwestern and northeastern sections of the service area (Figure 6). 


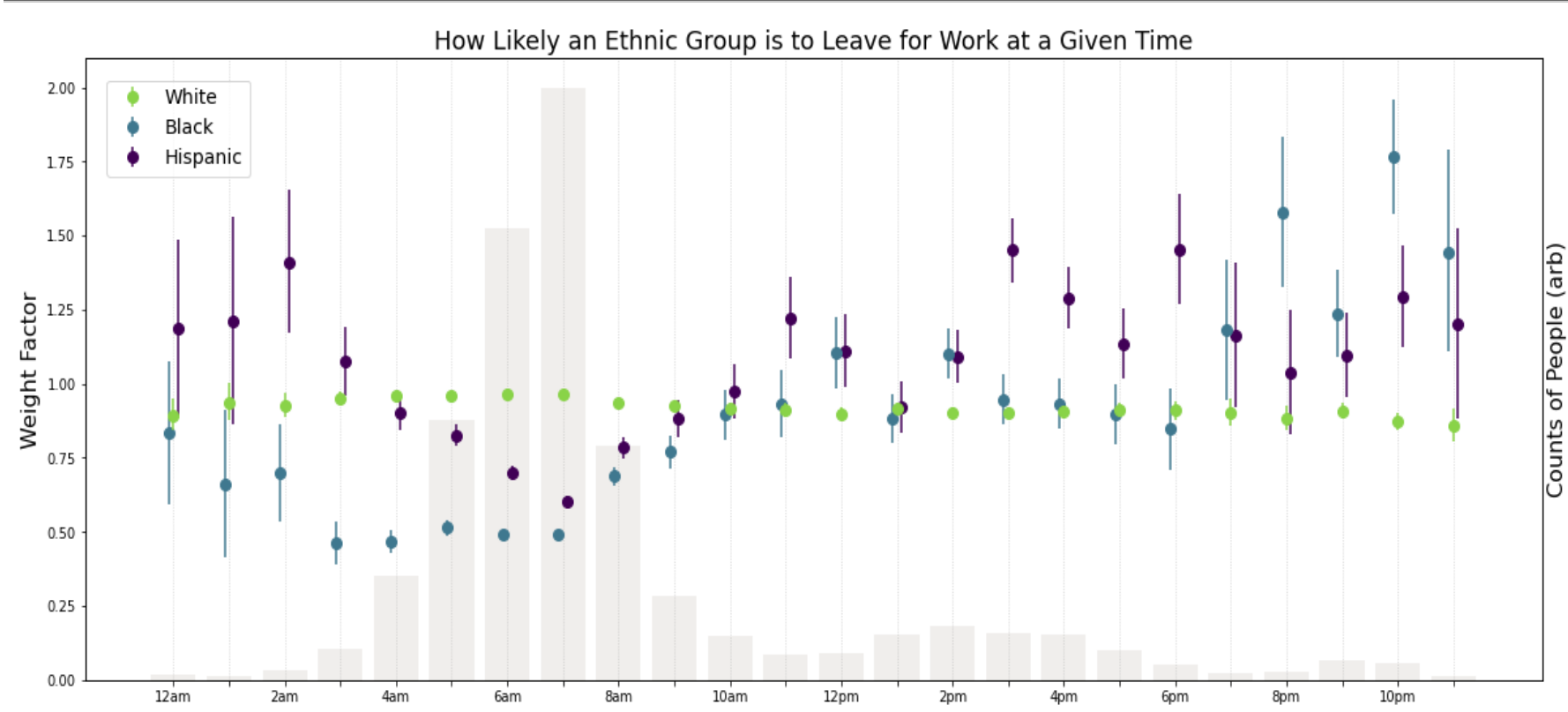

Figure 5: Demographics of Departure Time to Work. A histogram representing the relative amount of people who depart for work at a given time in Wisconsin is shown in grey in the background. The data was obtained from the American Community Survey Microdata sample and is representative of Wisconsin. The colored points represent the likelihood of an ethnic group to be departing for work above what would be expected from a non-racially dependent departure time. For example, given a population that is $75 \%$ White, and $25 \%$ Black, we would expect those same ratios of people to leave for work at $10 \mathrm{pm}$ if the departure time does not depend on race. Instead, if sampling 100 people who leave for work at $10 \mathrm{pm}$ in Wisconsin, we see that 50 are Black and 50 are White, we can assign a weight factor for Black citizens that is 1.5, and .5 for White citizens; a Black citizen is 1.5 times more likely to leave for work at $10 \mathrm{pm}$ than would be fair in a race-independent expectation of work departure time. From this plot it is important to note the three highest peaks in total people departing: $\sim 7 \mathrm{am}, \sim 2 \mathrm{pm}$, and $\sim 10 \mathrm{pm}$. $7 \mathrm{am}$ is of note for its higher White factor, while $2 \mathrm{pm}$ and $10 \mathrm{pm}$ reflect higher Black and Hispanic factors. Note that $10 \mathrm{pm}$ is the highest discrepancy in weight factor for Black people, and 2am for Hispanic people. (U.S. Census Bureau 2019(b))

\section{Route design: spacing stops and transporting} workers

Bus networks are often the result of a long legacy of continual expansions, minor additions and modifications that span multiple political and planning administrations and sometimes multiple generations of residents. The changes administered to bus network systems are a layering of differing visions, priorities, and objectives, leading to inefficiencies and flaws in the scheduling and routing of buses that deter riders and fail to meet transit organizations' mission or communities' needs. When Madison Metro transit riders were surveyed in 2015, "time waiting for buses" and "travel time on buses" were two of the five issues most in need of improvement (MPO 2015). In that survey more than $60 \%$ of riders $(68 \%)$ were commuting between home and work or school (MPO 2015). Transit organizations often list transport of residents to jobs as a primary objective, with an emphasis on inclusion of diverse racial, ethnic, and socioeconomic groups
(Metro Transit 2019; TriMet n.d.; SFMTA n.d.). The existing method of bus network development requires recurring modifications that act in a systematic manner, considering entire routes or multiple routes in a region of the network. This strategy can be especially effective in medium sized metro areas, such as Dane County, as they typically offer less complexity and fewer points of integration between different types of transit (e.g. subway, ferry, etc.). Two strategies that have proven effective in increasing efficiency of bus transit are bus stop balancing (SORTA/Metro n.d.; El-Geneidy et al. 2006) - ensuring bus stops are appropriately spaced - and route schedule design focused on diverse commuters with high reliance on the bus system (Alam 2009; Paulley 2006).

Utilizing optimal spacing of bus stops based on the terrain and walkability of an area can increase the speed of the bus, decrease travel travel time, and allow more frequent service with the same number of 

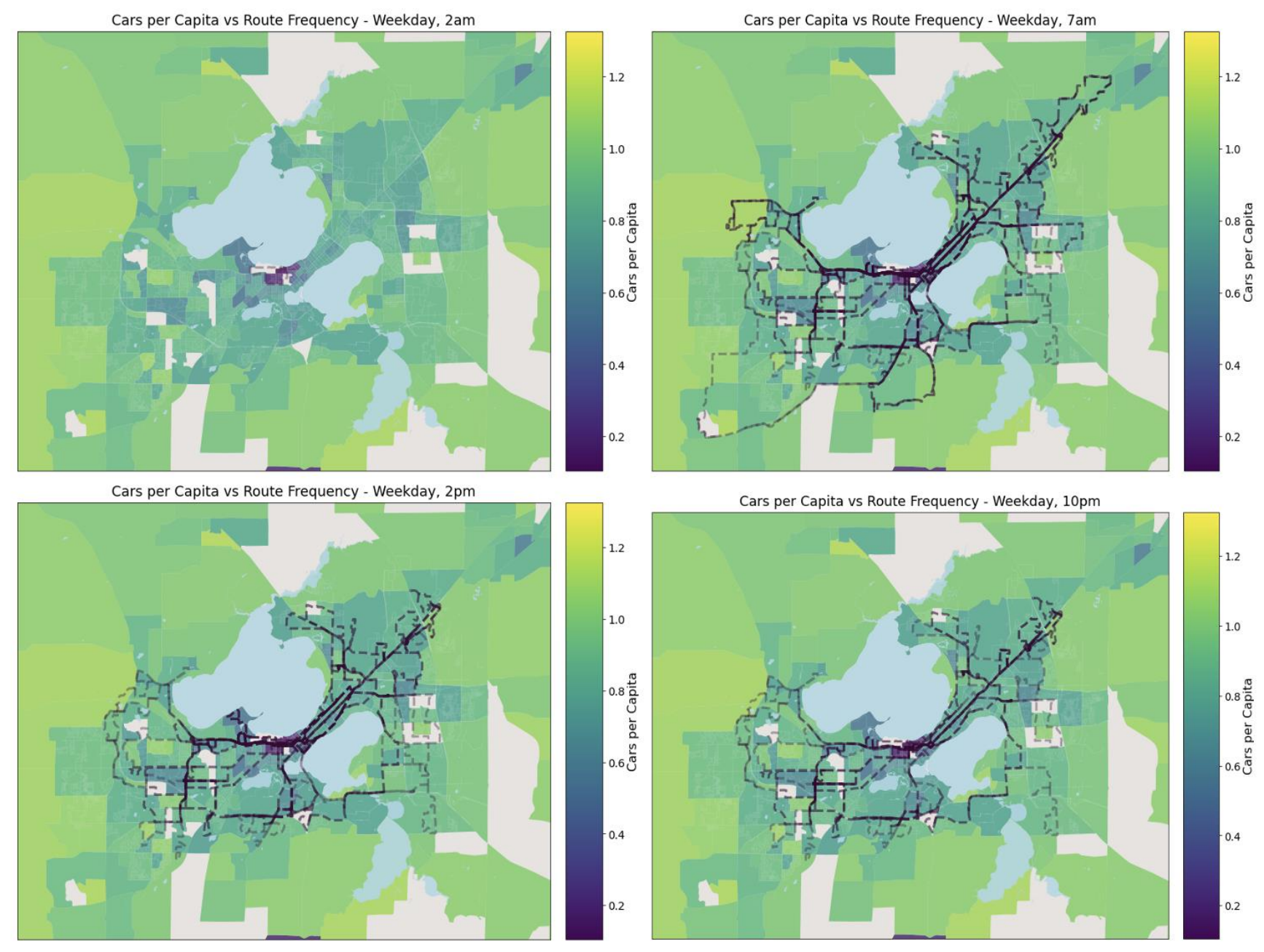

Figure 6: Car Ownership and Service Routes. Given the interesting times noted in figure 4: 2am, 7am, 2pm and $10 \mathrm{pm}$, this plot shows the frequency of route service at a given time indicated by the opaqueness of the lines overlaid on a density map of car ownership. Grey areas had no data available for the 2018 American Community Survey. In some low car ownership neighborhoods route service discontinues in off-peak hours (before 6am, $9 \mathrm{am}-3 \mathrm{pm}, 6 \mathrm{pm}$ and later). While the lowest cars per capita can be seen around the isthmus, there are other notably low-rate areas farther out that are not being as well serviced by the bus system. (City of Madison n.d.; U.S. Census Bureau 2019).

bus hours. For example, the San Francisco Metropolitan Transit Agency increased bus speeds 4$14 \%$ by shifting the spacing and frequency of bus stops from 6 stops per mile, to 2.5 stops per mile (Boyle 2013). Decreasing the distance between bus stops was implemented following a rider survey in which $61 \%$ of respondents commented they would be willing to walk longer distances if buses moved more quickly (SFMTA 2019). In Portland (OR), the transit authority TriMet, increased the average spacing between bus stops by approximately 90 feet and observed a $5.7 \%$ increase in trip speed, with no associated decrease in ridership (El-Geneidy et al.
2006). This change was part of TriMet's Streamline Project, which involved removing all stops in a route besides "anchor" stops at major intersections and transfer points, then placing new stops between the anchors based on strict spacing standards (Koonce et al. 2006). Analysis of Portland's bus stop balancing effort identified even greater capacity for increasing speeds with minor complimentary modifications to the route schedule (El-Geneidy et al. 2006). Cincinnati $(\mathrm{OH})$, a city located in the Midwest and similar to Madison in climate and size, is currently in phase III of a bus stop balancing effort called FAStops through the transit authority SORTA. SORTA initially 
piloted the program on five routes after rider surveys indicated faster trips as one of their three highest priorities. The stop balancing effort was successful with four of the five routes consistently running ahead of schedule (SORTA/Metro n.d.). In the last year, half of the 42 current routes have expanded to incorporate more efficient bus stop spacing. Optimizing stop spacing provides a straightforward strategy to increase bus speeds and reliability with demonstrated efficacy in a variety of cities across America.

Bus networks transport community members for a variety of different purposes including recreation, completing errands, attending religious services, or seeking medical treatment. However, most transit riders are commuting, with greater than $50 \%$ of travelers traveling between either work or school and home (Neff and Pham 2007; Statista n.d). As such, public transportation planning entities like Metro Transit provide significant transit resources to transport residents to employment centers like the Capitol and the University of Wisconsin-Madison campus. This is reflected in the central role these two locations play in the bus route network (Figure 1). Transit networks that use residential and employment centers as frequently visited nodes have been shown to increase and enable upward mobility by expanding the locations where individuals can work and live (Alam 2009; Blumenberg and Pierce 2014; Sanchez 2008). Yet, for transit networks to realize their full economic development potential, service schedules must be compatible with the needs of a diverse set of commuters by expanding service targeted to demand. Two points of misalignment come from service hours and route headways. Transit studies find that while low-wage workers are less likely to have access to personal automobiles and more likely to use transit, they are also more likely to commute during non-peak hours (Pucher and Renne 2003). Currently, the Metro Transit service area decreases during the middle of the day and late at night, with substantial reduction in frequency of routes further from the Capitol (Figure 4). Bus service is essentially non-existent by early morning, with only a single route in service at 2am (Figure 4). In addition, bus routes that offer hourly service provide limited benefit to commuters with long wait times if they miss the bus, leading to reduced flexibility and little room for error when riding. When riders in seven major US cities were surveyed about important areas of improvement for bus transit, frequency and reliability was the most common response (Higashide and Buchanan 2019). Misalignment of scheduling and service times can contribute to the dramatic underperformance of the bus system, specifically among marginalized communities. Bus transit networks can provide an effective commuting alternative when taking into account details of the neighborhoods and local communities they are serving.

\section{Recommendations for improving route design}

We recommend adoption of a standard stop spacing of 1000-2500 feet or 0.2-0.5 miles, reflecting approximately a 4-10 minute walk. Metro Transit serves an urban-rural region so exceptions should be made for areas with limited walkability such as those lacking sidewalks, and those with a high density of riders with limited mobility, including senior centers and assisted living facilities. This range is slightly greater than the minimum spacing recommendations for densely populated metro areas such as New York City (757 feet) but employing a distance similar to that of lower density cities like Seattle (1320 ft). We would expect that consolidating bus stops in this fashion would both increase transit speed as well as increase adherence to schedules (Bowman 1981; SORTA/Metro n.d.; Sterman and Schofer 1976; Turnquist 1978). However, community pushback to removing or redistributing stops can present a challenge, and so changes must be planned carefully, and benefits explained clearly.. A bus requires approximately 25 seconds to slow down, stop and then re-enter traffic, but this time can be much longer depending on the number of passengers boarding or exiting the bus (Huan and Bertini 2001; Rajbhandari et al. 2003; Reilly 2000) with lost transit time potentially rising into the minutes. The variability in the amount of time spent at each stop also makes adherence to the schedule more difficult. Consolidation of stops will affect average bus speeds, but we do not expect overall numbers of passengers to change, as they will be distributed among remaining stops. For example, if the average stop distance for route 4 was increased from 0.16 miles to 0.21 miles, this would lead to the elimination of approximately 11 stops and a decrease in transit time of 5.5 minutes. Fewer stops could allow for more amenities at the remaining stops, such as shelters, trash cans, and benches, which have been shown to decrease perceived wait times (Yingling et al. 2016). 
Improved stop amenities have also been shown to increase ridership on fixed routes and decrease requests for paratransit (Kim et al. 2020), a service Metro Transit operates at almost 12 times the expense of fixed route service per passenger trip. The seasonal climate of Wisconsin lends additional value to amenities such as shelters, especially in the winter months.

Although multiple initiatives from Metro Transit state an objective of providing equitable service across a variety of communities (City of Madison 2017; Metro Transit 2019), the route network continues to prioritize traditional commuting times centered around the downtown-campus area. This leads to potential underservice of communities of color and those populations with mobility challenges due to decreased car access. These two groups also overlap in several geographic areas (Figure 4, Figure 6) further aggravating this phenomenon of underservice.

We recommend substantially increased bus service focusing on areas with low car ownership, allowing for the incorporation of bus transit into residents' commutes. Several areas with relatively few cars per capita experience low frequency service even during the busiest service times, such as 7am (Figure 6). Decreasing route headways from 1 hour to 30 minutes in these low-car areas would be a vast improvement, with optimization analysis suggesting compatibility with features of Metro Transit's network, such as bus size and demand (dell'Olio et al. 2012). This is not particularly surprising, given that Metro Transit currently supports 30-minute route headways on many routes. We would expect increased frequency to drive increased utilization given the potential high demand in these communities. Lower car availability has been associated with increased transit use (Paulley 2016), while the availability of convenient public transportation disincentivizes individuals from purchasing cars (Cullinane 2002). Among US riders who increased their bus transit usage over the last two years, frequency was stated as the most important improvement to the bus system (Pucher and Renne 2003). Two possible pilot routes are route 13 and route 40 , which currently operate at hourly frequencies throughout the day and pass through areas of southern Madison with relatively low car density. These routes also both terminate at the South
Transfer Point where all other routes are operating with 30-minute route headways for at least some part of the day, providing a potentially synergistic effect to these recommended service changes. Increasing service frequency for routes across the network would be limited by physical resources such as buses and drivers.

We also recommend expanding service hours into midday to accommodate more non-traditional work schedules, with a specific focus on minority and underserved communities. Given the minimal amount of service currently supplied across the network in this time period, we would expect marginal strain on bus resources. Access to public transportation for commuting has been shown to help increase job accessibility (Cervero 2008) and help individuals maintain employment (Blumenberg 2014), especially for low-income individuals or those transitioning from social welfare programs (Faulk 2010; Alam 2009). Two routes that could potentially benefit from this service expansion are route 11 and route 33, which pass through several minority communities but do not currently provide service between 10am and 3pm. A pilot program utilizing one or both routes would allow for an analysis of the efficacy of these service changes. We expect that this would increase ridership during the new service hours. Although expanding service hours into midday for routes appears to be the most feasible from a bus operator standpoint, service in the late night or early morning would also benefit non-traditional commuters. Although this increase in service hours would face fewer limitations on physical resources such as buses, late night service may require increased investment in public safety, such as lighting or security measures, to entice both riders and drivers.

\section{Conclusion}

The mission statement of Metro Transit shares many characteristics with those of transit agencies across the country, "to provide safe, reliable, convenient and efficient public transportation" (Metro Transit 2019). Yet, Metro Transit serves a mosaic of communities in the Greater Madison Urban Area that is in many ways unique. Metro Transit can improve the service it provides by modifying its route network in ways that are both standardized as well as specifically tailored to these communities. In the interest of utilizing both 
strategies, we have recommended three modifications and considerations:

1) Adoption of a standardized spacing of 1000-2500 feet between stops, with exceptions made for non-walkable areas, or those with high density of riders with disabilities

2) Increased service frequency, specifically focused on areas with low levels of car ownership

3) Expanded service for non-traditional commuter hours such as midday, especially for communities with large numbers of African American and Latino residents

We recommend each of these modifications be first adopted in a pilot to allow for small scale analysis of both their tangible objective effects on operation as well as their subjective effects on rider's attitudes toward the transit system. Each recommendation could be piloted on a single route, with increased stop spacing, increased service frequency, and expanded service hours being piloted on routes 4,13 , and 11 , respectively. As described above, route 11 would receive service between $10 \mathrm{am}$ and $3 \mathrm{pm}$ and route 13 would decrease time between buses from one hour to 30 minutes. Tracking of bus location and speed is

\section{References}

Alam, Bhuiyan Monwar. 2009. "Transit accessibility to jobs and employment prospects of welfare recipients without cars: A study of Broward County, Florida, using geographic information systems and an econometric model." Transportation research record 2110(1): 78-86. https://doi.org/10.3141/2110-10

Atiyeh, Clifford. 2020. "Some Takeaways on 2016, the Best Year Ever for U.S. Auto Sales." Car and Driver, 23 July 2020, www.caranddriver.com/news/a15343691/some -takeaways-on-2016-the-best-year-ever-for-u-sauto-sales/.

Bailey, Linda, and Robert Puentes. 2016. "Improving Metropolitan Decision Making in Transportation: Greater Funding and Devolution for Greater Accountability." Brookings, October 1. Accessed 28 July 2020. www.brookings.edu/research/improvingmetropolitan-decision-making-in-transportationgreater-funding-and-devolution-for-greateraccountability/ already performed by Madison Metro and could be used to measure effects of bus stop consolidation. Passenger boarding numbers and onboarding surveys could be used to track the effects of changes in service frequency and hours of operation on utilization and perception of the bus system. We expect the three recommended modifications to decrease transit time and deviations from posted schedules, increase ridership, and improve riders' opinions on transit, reflected in future onboarding surveys of riders, specifically in the categories: "Time waiting for buses", "Travel time on buses", "Convenience of routes", and "Overall satisfaction" (MPO 2015).

Although we expect these modifications to be effective, the analysis performed here relies on a relatively limited dataset. More detailed data about bus speed or traffic conditions would allow for increased stop spacing to be targeted to areas with high levels of congestion. Including data on sidewalks, curb cuts, or other measures of pedestrian capacity and accessibility would allow for stop consolidation to be targeted to the most pedestrianfriendly areas. Additional census, demographic and survey information could be used to target new routes or help identify potential route modifications to provide better service to a wider, more diverse population.
Blumenberg, Evelyn, and Gregory Pierce. 2014. "A driving factor in mobility? Transportation's role in connecting subsidized housing and employment outcomes in the moving to opportunity (MTO) program." Journal of the American Planning Association 80(1): 52-66. https://doi.org/10.1080/01944363.2014.93526 7

Bowman, Larry A., and Mark A. Turnquist. 1981. "Service frequency, schedule reliability and passenger wait times at transit stops." Transportation Research Part A: General 15(6): 465-471. https://doi.org/10.1016/0191-2607(81)90114X

Boyle, Daniel K. 2014. "Commonsense Approaches for Improving Transit Bus Speeds." Washington, D.C. The National Academies Sciences Engineering Medicine. https://doi.org/10.17226/22421. 
Center for Urban Transportation Research University of South Florida. 2020. "Integrating Equity into MPO Project Prioritization." Last modified January 17, 2020. Accessed October 10, 2020. www.cutr.usf.edu/2020/01/integrating-equityinto-mpo-project-prioritization/

Cervero, Robert, and Jennifer Day. 2008. "Suburbanization and transit-oriented development in China." Transport Policy 15(5): 315-323. https://doi.org/10.1016/j.tranpol.2008.12.011

City of Madison, 2017, "Madison in Motion Transportation Plan." Accessed November 11, 2020 https://www.cityofmadison.com/transportation /documents/MIM/MIMReportWeb.pdf

City of Madison. n.d. "Metro Transit Bus Routes" Accessed May 18, 2020

https://data-

cityofmadison.opendata.arcgis.com/datasets/b6c 6c86f30bb44d8be06b339aabaa8f5 18? geometry $=-90.234 \% 2 \mathrm{C} 42.906 \% 2 \mathrm{C}-88.575 \% 2 \mathrm{C} 43.257$

Clark, Hugh. 2017. "Who Rides Public Transportation." Washington, DC: American Public Transportation Association. www.apta.com/research-technicalresources/research-reports/who-rides-publictransportation/.

d'Arcier, Bruno Faivre. 2014. "Measuring the performance of urban public transport in relation to public policy objectives." Research in Transportation Economics 48: 67-76. https://doi.org/10.1016/i.retrec.2014.09.033

dell'Olio, Luigi, Angel Ibeas, and Francisco Ruisánchez. 2012. "Optimizing bus-size and headway in transit networks." Transportation 39 (2): 449-464. https://doi.org/10.1007/s11116-011-9332-2

El-Geneidy, Ahmed M., James G. Strathman, Thomas J. Kimpel, and David T. Crout. 2006. "Effects of bus stop consolidation on passenger activity and transit operations." Transportation Research Record 1971(1): 32-41. https://doi.org/10.1177/036119810619710010 $\underline{4}$

Environmental Protection Agency. 2020. "Inventory of U.S. Greenhouse Gas Emissions and Sinks." Last modified February 11, 2021. Accessed December 20, 2020, www.epa.gov/ghgemissions/inventoryus-greenhouse-gas-emissions-and-sinks.

Fan, Yingling, Andrew Guthrie, and David Levinson. 2016. "Waiting time perceptions at transit stops and stations: Effects of basic amenities, gender, and security." Transportation Research Part A: Policy and Practice 88: 251-264. https://doi.org/10.1016/j.tra.2016.04.012

Hall, Jonathan D., Craig Palsson, and Joseph Price. 2018. "Is Uber a substitute or complement for public transit?." Journal of Urban Economics 108: 36-50. https://doi.org/10.1016/i.jue.2018.09.003
Higashide, S., and M. Buchanan. 2019. "Who's on board 2019 how to win back America's transit riders." Transit

Center. https://transitcenter.org/publication/whos-onboard-2019/

Hughes-Cromwick, MacPherson, Matthew Dickens. 2020. "2020 APTA public transportation fact book. Washington, DC: American Public Transportation Association. $\quad$ https://www.apta.com/wpcontent/uploads/APTA-2020-Fact-Book.pdf

Katz, Bruce, et al. "TEA-21 Reauthorization: Getting Transportation Right for Metropolitan America." Brookings, July 28. Accessed November 1, 2020. www.brookings.edu/research/tea-21reauthorization-getting-transportation-right-formetropolitan-america/.

Kim, Ja Young, Keith Bartholomew, and Reid Ewing. 2020. "Another one rides the bus? The connections between bus stop amenities, bus ridership, and ADA paratransit demand." Transportation Research Part A: Policy and Practice 135: 280-288. https://doi.org/10.1016/j.tra.2020.03.019

Kneebone, Elizabeth. "Job Sprawl Stalls: The Great Recession and Metropolitan Employment Location." Brookings, July 29. Accessed July 10, 2020.

www.brookings.edu/research/job-sprawl-stallsthe-great-recession-and-metropolitanemployment-location/.

Koonce, Peter, Paul Ryus, David Zagel, Young Park, and Jamie Parks. "An evaluation of comprehensive transit improvements-TriMet's Streamline Program." Journal of Public Transportation 9(3): 6. http://doi.org/10.5038/2375-0901.9.3.6

Legrain, Alexander, et al. 2015. "Am Stressed, Must Travel: The Relationship between Mode Choice and Commuting Stress." Transportation Research Part F: Traffic Psychology and Behaviour 34: 141-151. https://doi.org/10.1016/j.trf.2015.08.001

Li, Huan, and Robert L. Bertini. 2009. "Assessing a model for optimal bus stop spacing with high-resolution archived stop-level data." Transportation Research Record 2111(1): 24-32. https://doi.org/10.3141/2111-04

Litman, Todd. 2013. "Transportation and Public Health." Annual Review of Public Health 34(1): 217-233. https://doi.org/10.1146/annurev-publhealth031912-114502

Madison Area Transportation Planning Board (MPO). November 2015. "2015 Metro Transit Onboard Survey" Accessed November 12, 2020 https://www.greatermadisonmpo.org/planning/ documents/OBSExecutiveSummaryMP0.pdf 
Mallett, William J. 2018. "Trends in Public Transportation Ridership: Implications for Federal Policy." Congressional Research Services, March 26. Accessed October 5, 2020. https://crsreports.congress.gov/product/pdf/R/ $\underline{\mathrm{R} 45144}$

Mattson, Jeremy. 2008. "Effects of Rising Gas Prices on Bus Ridership for Small Urban and Rural Transit Systems." Upper Great Plains Transportation Institute, June. Accessed September 3, 2020. https://www.ugpti.org/resources/reports/down loads/dp-201.pdf

Metro Transit. June 2019. "Metro Transit (Transit Utility)" Accessed October 23, 2020 https://www.cityofmadison.com/council/docum ents/resource/14-31T-MT.pdf

Metro Transit. 2020 "2019 Annual Report." Accessed October 15, 2020

https://www.cityofmadison.com/metro/docume nts/annual-reports/2019.pdf

Neff, John, and Larry Pham. 2007. A profile of public transportation passenger demographics and travel characteristics reported in on-board surveys. Washington, D.C.: American Public Transportation Association. $\quad$ https://filecenter.santaclarita.com/transit/APTA\%20Passenger\%20Cha racteristics.pdf

Nelson, Arthur C., Thomas W. Sanchez, James F. Wolf, and Mary Beth Farquhar. 2004. "Metropolitan planning organization voting structure and transit investment bias: Preliminary analysis with social equity implications." Transportation research record 1895(1): 1-7. https://doi.org/10.3141/1895-01

Paulley, Neil, Richard Balcombe, Roger Mackett, Helena Titheridge, John Preston, Mark Wardman, Jeremy Shires, and Peter White. 2006. "The demand for public transport: The effects of fares, quality of service, income and car ownership." Transport policy 13(4): 295-306. https://doi.org/10.1016/i.tranpol.2005.12.004

Pine, Randall, James Niemeyer, and Russell Chisholm. 1998. Transit Scheduling: Basic and Advanced Manuals. Washington, D.C.: Transportation Research Board.

Plecher, H. 2020. "United States - Urbanization 2019." Statista, Accessed November 15, 2020, www.statista.com/statistics/269967/urbanizatio n-in-the-united-states/.

Pucher, John, and John L. Renne. 2003. "Socioeconomics of urban travel. Evidence from the 2001 NHTS." Transportation Quarterly 57(3): 49-77 https://www.sharetheroad.ca/pdf/(Pucher)Socioeconomics-of-Urban-Travel.pdf
Rajbhandari, Rajat, Steven I. Chien, and Janice R. Daniel. 2003. "Estimation of bus dwell times with automatic passenger counter information." Transportation Research Record 1841(1): 120127. https://doi.org/10.3141/1841-13

Reilly. 2000. Highway capacity manual 2000. Washington, DC: Transportation Research Board.

Richter, Felix. 2019. "Infographic: Cars Still Dominate the American Commute." Statista Infographics, Last modified May 29. Accessed September 13, 2020, www.statista.com/chart/18208/means-oftransportation-used-by-us-commuters/.

Rodrigue, Jean-Paul. 2020. The geography of transport systems, fifth edition. New York, NY: Routledge.

Sanchez, Thomas. "An Inherent Bias? Geographic and Racial-Ethnic Patterns of Metropolitan Planning Organization Boards." Brookings, July 28. Accessed August 13, 2020. www.brookings.edu/research/an-inherent-biasgeographic-and-racial-ethnic-patterns-ofmetropolitan-planning-organization-boards/.

Sanchez, Thomas W. 2008. "Poverty, policy, and public transportation." Transportation Research Part A: Policy and Practice 42(5): 833-841. https://doi.org/10.1016/j.tra.2008.01.011

San Francisco Municipal Transportation Authority. "SFMTA Vision and Mission Statement" Accessed October 23, 2020 https://www.sfmta.com/aboutus/sfmta-strategic-plan/mission-vision

San Francisco Municipal Transportation Authority. 2019. "Ridership Survey 2018" Accessed January 17, 2021

https://www.sfmta.com/sites/default/files/repo rts-and-documents/2018/12/12-1818 item 11_muni_rider_survey 2018.pdf

Schrag, Zachary M. "Urban Mass Transit In The United States." Accessed September 17, 2020. eh.net/encyclopedia/urban-mass-transit-in-theunited-states/

SORTA/Metro. n.d. "Frequently Asked Questions Phase 3" Accessed October 3, 2020

https://www.gometro.com/uploads/FAStops/FAStops\%20FAQs \%20Phase\%203_1.pdf

Statista. "Trip purposes in U.S. public transit, according to respondents from 2008 to 2015" Accessed October 20, 2020 https://www.statista.com/statistics/715217/tri p-purposes-in-us-public-transit/

Sterman, Brian Philip, and Joseph L. Schofer. 1976. "Factors affecting reliability of urban bus services." Journal of Transportation Engineering 102(1): 147-159.

TriMet. "Our Organization" Accessed October 23, 2020 https://trimet.org/about/organization.htm 
Turnquist, Mark A. 1978. "A model for investigating the effects of service frequency and reliability on bus passenger waiting times." Transportation Research Record 663: 70-73. http://onlinepubs.trb.org/Onlinepubs/trr/1978/ 663/663-012.pdf

U.S. Census Bureau. 2019(a). "American Community Survey 5-Year Data Profile 2014-2018: Dane County, Employment, 2018 " Accessed May 18, $2020 \underline{\mathrm{V}}$

U.S. Census Bureau. 2019(b). "Public Use Microdata Sample (PUMS): 2018." Accessed November 3, 2020 https://www.census.gov/programssurveys/acs/microdata.html

U.S. Census Bureau. n.d. "United States Census Bureau QuickFacts." Accessed November 12, 2020 https://www.census.gov/quickfacts/fact/table/v eronacitywisconsin,middletoncitywisconsin,fitch burgcitywisconsin,danecountywisconsin/PST045 $\underline{219}$
U.S. Department of Transportation Federal Highway Administration. 2014. "Household Travel in America." Last modified November 7, 2014. Accessed November 13, 2020. www.fhwa.dot.gov/policy/2010cpr/chap1.cfm

Verbavatz, Vincent, and Marc Barthelemy. 2019. "Critical Factors for Mitigating Car Traffic in Cities." Plos One https://doi.org/10.1371/journal.pone.0219559

Walker, Jarrett. 2012. Human Transit How Clearer Thinking Can Enrich Our Communities and Lives. Washington, DC: New Island Press.

Welch, Timothy F., and Sabyasachee Mishra. 2013. "A Measure of Equity for Public Transit Connectivity." Journal of Transport Geography (33):

$29-41$ https://doi.org/10.1016/i.jtrangeo.2013.09.007

Zeid, Maya Abou. 2009. Measuring and modeling activity and travel well-being. PhD diss., Massachusetts Institute of Technology.

Justin McKetney is a PhD Student in the Integrated Program in Biochemistry at the University of WisconsinMadison, where his research focuses on developing and utilizing mass spectrometry-based proteomic tools to investigate human health. He has specifically focused on increasing understanding of molecular protein signatures for aging, stress, and Alzheimer's disease. Justin received his BS in Cell and Molecular Biology from San Diego State University.

Edna Angelica Trujillo is a Ph.D. student in Chemical Biology (Chemistry Department) at the University of Wisconsin-Madison where she studies the application and technology of mass spectrometry in the field of BioAnalytical Chemistry. She has a Ph.D. minor in Life Science Communication and utilizes her training to create science curriculum for non-expert audiences at the Wisconsin Science Festival and Madison elementary schools. She is passionate about making science more accessible and mentoring young adults on how to apply to college and the first-generation college experience. A new member of the Catalysts for Science Policy, she has pioneered in leveraging big data for designing inclusive science policy. Edna is a first generation Latinx college student and received her AS in Chemistry from Santa Barbara Community College and then transferred to Humboldt State University where she received her BS in Chemistry.

Megan Tabbutt is a Ph.D. student in Physics at the University of Wisconsin-Madison where she studies Cosmology, specifically large-scale structure, using optical imaging surveys. She is a member of the Dark Energy Survey (DES) and the Rubin Observatory Legacy Survey of Space and Time (LSST). In addition, she is applying for the M.S. program in Computer Science to be completed along with her Ph.D. She is a National Defense Science and Engineering Graduate Fellow and a member of the Catalysts for Science Policy. She is passionate about civil hacking using data analysis and enjoys spending free time on such projects. She received her B.S. in Physics, Astrophysics and Math from the University of Wisconsin - Madison.

Brittany Baur is a Postdoctoral Researcher at the Wisconsin Institute for Discovery at the University of Wisconsin-Madison. She holds a Ph.D. in Computational Sciences and a M.S. in Bioinformatics from Marquette University. She studies the role of the 3-dimensional structure of the genome in gene regulation and disease. She is an active member of Catalysts for Science Policy and is passionate about effective science communication and leveraging data science to inform policy decisions. 


\section{Acknowledgements}

The authors would like to thank the City of Madison for the creation and maintenance of the City of Madison Open Data Portal, from which much of the data here is derived. We thank Catalysts for Science Policy (CaSP) and its members for both inspiring an interest in science policy and providing a forum for development of many of the ideas included in this manuscript. Specifically, we would like to thank Evan Linck, Tyler Peterson, and Maia Gumnit for helping to sustain the project in its early conception. We would also like to thank Dr. Tyler Caraza-Harter who provided feedback and guidance throughout the development process. 